\title{
Effect of a Dietary Supplement Containing Raspberry Ketone on Cytochrome P450 3A Activity
}

Masayuki Sekizuka"\#, Jing Wei Qi ${ }^{2 \#}$, Tohru Aomori ${ }^{2,3,4}$, Yuko Okada', Katsunori Nakamura ${ }^{5}$, Takuya Araki ${ }^{2,3}$, Ryuya Horiuchi ${ }^{2}$, Shin Ohta ${ }^{6}$, Tomonori Nakamura ${ }^{2,3}$ and Koujirou Yamamoto ${ }^{2,3 *}$

${ }^{1}$ Faculty of Pharmacy, Takasaki University of Health and Welfare 37-1 Nakaoorui-machi, Takasaki, Gunma 370-0033, Japan

${ }^{2}$ Department of Clinical Pharmacology, Gunma University Graduate School of Medicine, 3-39-22 Showa-machi, Maebashi, Gunma 371-8511, Japan

${ }^{3}$ Department of Pharmacy, Gunma University Hospital, 3-39-15 Showa-machi, Maebashi, Gunma 371-8511, Japan

${ }^{4}$ Center for Medical Education, Gunma University Graduate School of Medicine, 3-39-22 Showa-machi, Maebashi, Gunma 371-8511, Japan

${ }^{5}$ Educational Research Center for Clinical Pharmacy, Nagoya City University Graduate School of Pharmaceutical Sciences,3-1 Tanabe-dori, Mizuho-ku, Nagoya, Aichi 467-8603, Japan

${ }^{6}$ Department of Pharmaceutical Health Care and Science, Tokyo University of Pharmacy and Life Science, 1432-1 Horinouchi, Hachiouji, Tokyo 192-0355, Japan

\#Contributed Equally

\section{Abstract}

Objective: Various herbal medicines and dietary supplements are known to alter the effects of drugs and cause severe complications. One of the most famous examples is St. John's wort, which promotes an increase of cytochrome P450 2C9 (CYP2C9), CYP2C19, and CYP3A4 expression, and reduces the effects of a large number of drugs. Raspberry ketone, an aromatic ingredient extracted from raspberries, is sold in Japan as a herbal supplement with a claimed slimming effect; however, its effect on CYP activity is unknown. To clarify the risk of an interaction between raspberry ketone-related supplements and CYP3A substrates, we performed an in vivo pharmacokinetic study using rats.

Methods: We investigated the effect of the oral administration of raspberry ketone on the pharmacokinetics of midazolam, a typical CYP3A substrate, in rats. St. John's wort, as a positive control, and raspberry ketone tablets at a dose of $50 \mathrm{mg} / \mathrm{kg}$ were administered every $12 \mathrm{~h}$ for 7 days, and at $24 \mathrm{~h}$ after the final treatment, $10 \mathrm{mg} / \mathrm{kg}$ midazolam was administered orally. The plasma concentration of midazolam was analyzed by high-performance liquid chromatography.

Results: Oral clearance of midazolam in the St. John's wort-treated group increased to $161 \%$ of that observed in the control group. Conversely, there was no significant difference between the raspberry ketone-treated and control groups. The mean residence time was essentially the same in all groups.

Conclusion: Because raspberry ketone is considered to suppress the accumulation of body fat, it is mainly taken by young healthy women for weight loss. Considering this population, information about the interaction of raspberry ketone with oral contraceptives, which are substrates of CYP3A, is of clinical importance. In this study, raspberry ketone was found to have little impact on CYP3A activity, unlike St. John's wort. These data indicate the low risk of an interaction between raspberry ketone-related supplements and many drugs metabolized by CYP3A.

Keywords: CYP3A; Raspberry ketone; Herbal supplement; Interaction; Rat; Pharmacokinetic parameters; St. John's wort

\section{Introduction}

The cytochrome P450 (CYP) family of enzymes is responsible for the oxidation of various xenobiotic chemicals, including drugs. The regulation of individual CYP enzymes is a complex subject, with examples of induction, direct inhibition, and stimulation. Nutrients and food additives can modify the activity of CYP enzymes and consequently influence the disposition of drugs. Various herbal medicines and dietary supplements are known to change the action of drugs and cause severe complications. One of the most famous examples is St. John's wort (SJW), which promotes an increase in CYP2C9 [1], CYP2C19 [2], and CYP3A4 [3] expression, while reducing the effects of warfarin [1,4], cyclosporine [5], oral contraceptives [6], and other medications.

Raspberry ketone, an aromatic ingredient extracted from raspberries, has been sold in Japan since 2002 as a herbal supplement with claimed slimming effects. The skeletal structure of raspberry ketone is partially similar to capsaicin, the principal component of capsicum fruits (Figure 1), which reportedly increases the secretion of catecholamines [7] and energy expenditure [8] while suppressing body fat accumulation [9]. Capsaicin is also a well-known inhibitor of CYP enzymes [10]. Raspberry ketone also reportedly decreases the body weight of obese rats [11]; however, its effect on CYP activity is unknown.

Since raspberry ketone suppresses the accumulation of body fat, mainly young healthy women may take it to reduce their weight. Considering the population who consume raspberry ketone, information about its interaction with oral contraceptives, which are substrates of CYP3A, is of clinical importance. In this study, we investigated the effect of the oral administration of raspberry ketone

*Corresponding author: Koujirou Yamamoto, Department of Clinical Pharmacology, Gunma University Graduate School of Medicine, 3-39-22 Showamachi, Maebashi, Gunma 371-8511, Japan, Tel: +81-27-220-8743; E-mail: koujirou@gunma-u.ac.jp

Received April 28, 2014; Accepted June 16, 2014; Published June 23, 2014

Citation: Sekizuka M, Qi JW, Aomori T, Okada Y, Nakamura K, et al. (2014) Effect of a Dietary Supplement Containing Raspberry Ketone on Cytochrome P450 3A Activity. Pharm Anal Acta 5: 302. doi:10.4172/2153-2435.1000302

Copyright: @ 2014 Sekizuka M, et al. This is an open-access article distributed under the terms of the Creative Commons Attribution License, which permits unrestricted use, distribution, and reproduction in any medium, provided the original author and source are credited. 


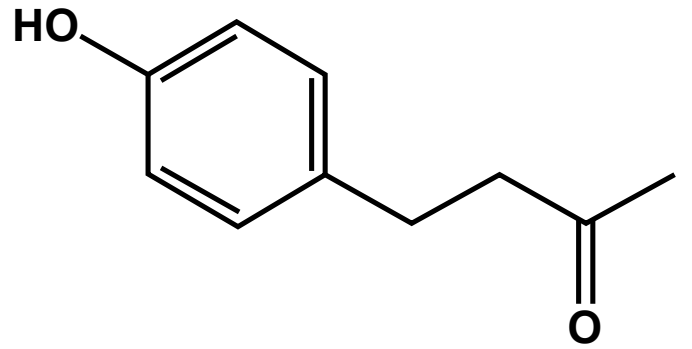

Figure 1: Structure of raspberry ketone.

on the pharmacokinetics of midazolam, a typical CYP3A substrate, in Wistar rats.

\section{Materials and Methods}

\section{Chemicals and materials}

Raspberry ketone was kindly supplied by Kanebo (Tokyo, Japan) as Vitarosso ${ }^{\circledR}$ tablets containing $16.7 \mathrm{mg}$ of raspberry ketone per tablet. The tablets also contained Gymnema sylvestris and adlay seed extracts, inositol, and ascorbic acid as minor constituents. SJW extract was kindly supplied by Fancl (Yokohama, Japan). Midazolam was purchased from Yamanouchi Pharmaceuticals (Tokyo, Japan) as an injection $\left(\right.$ Dormicum ${ }^{\circledR}$ ). Clonazepam, an internal standard for highperformance liquid chromatography (HPLC) analysis, was generously supplied by Sumitomo Pharmaceuticals (Osaka, Japan). All other chemicals and reagents were obtained from commercial sources and used without further purification.

\section{Animal experiments}

The animal experimental protocol was approved by the Animal Research Ethics Committee of Gunma University (Permit Number: 10-014), and its procedures were performed in accordance with the ethics guidelines of the committee. All surgery was performed under anesthesia, and all efforts were made to minimize suffering. Male Wistar rats (7 weeks of age, weighing 180-250 g) were purchased from Charles River (Tokyo, Japan). The rats were kept under a 12-h light/ dark cycle at $24 \pm 1^{\circ} \mathrm{C}$, and allowed free access to standard laboratory rodent chow and water.

Five rats were used in each group. In the raspberry ketone group, raspberry ketone tablets were crushed and suspended in saline and administered to the rats at a dose of $50 \mathrm{mg} / \mathrm{kg}$ every $12 \mathrm{~h}$ for 7 days [12]. SJW extract was suspended in saline and administered to the rats in the SJW-treated group at a dose of $1,000 \mathrm{mg} / \mathrm{kg}$ every $24 \mathrm{~h}$ for 7 days [13]. The doses of raspberry ketone and SJW were chosen according to previous reports $[12,13]$. The same volume of saline was administered every $12 \mathrm{~h}$ to the rats in the control group for the raspberry ketonetreated group and every $24 \mathrm{~h}$ to the rats in the control group for the SJW-treated group. On the $7^{\text {th }}$ day of treatment, the rats were fasted overnight. At $24 \mathrm{~h}$ after the final treatment with raspberry ketone or SJW, $10 \mathrm{mg} / \mathrm{kg}$ midazolam in a buffered solution was administered orally and blood samples were collected at $2,5,10,15,20,30,45,60$, $90,120,150$, and $180 \mathrm{~min}$ after administration. The blood samples were centrifuged immediately at $1,000 \times \mathrm{g}$ for $10 \mathrm{~min}$ to obtain plasma. The plasma samples were stored at $-20^{\circ} \mathrm{C}$ until HPLC analysis.

\section{HPLC}

The plasma concentration of midazolam was measured using
HPLC. Briefly, $0.1 \mathrm{~mL}$ plasma was mixed with $0.1 \mathrm{~mL}$ internal standard solution $(1 \mu \mathrm{g} / \mathrm{mL}$ clonazepam), $1 \mathrm{~mL}$ of $0.1 \mathrm{~mol} / \mathrm{L}$ borate buffer $(\mathrm{pH}$ $10.0)$, and $2.5 \mathrm{~mL} n$-hexane:dichloromethane $(1: 1, \mathrm{v} / \mathrm{v})$. The mixture was shaken for $10 \mathrm{~min}$ and then centrifuged at $3,000 \times g$ for $5 \mathrm{~min}$. The upper organic layer was transferred to a clean glass tube and evaporated to dryness at $40^{\circ} \mathrm{C}$. The dried residue was dissolved in $0.1 \mathrm{~mL}$ of $65 \%$ methanol, and a $20-\mu \mathrm{L}$ aliquot was injected into the HPLC system. A Waters 2960 separation module was used for the HPLC pump, and the absorbance at $245 \mathrm{~nm}$ was detected using a Waters 996 photodiodearray detector (Waters, Milford, MA, USA). The column was a YMC Pack Pro C18 ODS column (YMC, Tokyo, Japan) with a length of 250 $\mathrm{mm}$ and a diameter of $4.6 \mathrm{~mm}$, and maintained at $40^{\circ} \mathrm{C}$. The mobile phase was $65 \%$ methanol and pumped at a flow rate of $1.0 \mathrm{~mL} / \mathrm{min}$. The detection limit of midazolam was $50 \mathrm{ng} / \mathrm{mL}$.

\section{Data analysis}

The pharmacokinetics of midazolam after the oral administration of raspberry ketone or SJW were analyzed using the model-independent moment analysis method. The area under the plasma concentration curve (AUC) and area under the moment curve (AUMC) were calculated using the trapezoidal method from 0 to $180 \mathrm{~min}$. The oral clearance rate $\left(\mathrm{CL}_{\text {oral }}\right)$ and mean residence time $(\mathrm{MRT})$ of midazolam were calculated using the following equations:

\section{$\mathrm{CL}_{\text {oral }}=$ dose/AUC \\ $\mathrm{MRT}=\mathrm{AUMC} / \mathrm{AUC}$}

The apparent volume of distribution ( $\mathrm{Vd}$ ) divided by bioavailability (F) was calculated using the following equation:

\section{$\mathrm{Vd} / \mathrm{F}=\mathrm{MRT} \cdot \mathrm{CL}_{\text {oral }}$}

Comparisons of these values between the treated and control groups were performed using Welch's t-test.

\section{Results}

The plasma concentration profiles and pharmacokinetic parameters of midazolam in rats treated with raspberry ketone or SJW for 7 days are shown in Figure 2 and Table 1, respectively. The $\mathrm{CL}_{\text {oral }}$ of midazolam in the SJW-treated group increased to $161 \%$ of the
A

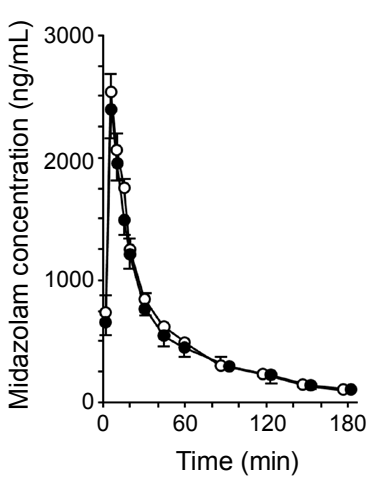

$\mathrm{B}$

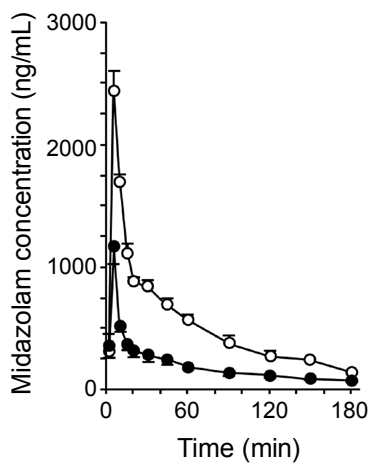

Figure 2: Concentration profile of midazolam in plasma after oral administration.

Closed circles: treated with raspberry ketone (100 mg/day) (A) or SJW (1000 $\left.\mathrm{mg} \cdot \mathrm{kg}^{-1} \cdot \mathrm{day}^{-1}\right)(\mathrm{B})$ for 7 days.

The open circles in panels $A$ and $B$ show the control group for each treated group.

Each symbol and vertical bar represents the mean \pm standard deviation of 5 rats. 


\begin{tabular}{|c|c|c|c|c|}
\hline & \multicolumn{2}{|c|}{ Raspberry ketone } & \multicolumn{2}{c|}{ St John's wort } \\
\hline & $\begin{array}{c}\text { Treated } \\
(\mathbf{n = 5})\end{array}$ & $\begin{array}{c}\text { Control } \\
(\mathbf{n}=\mathbf{5})\end{array}$ & $\begin{array}{c}\mathbf{S} \text { SW } \\
(\mathbf{n = 5}\end{array}$ & $\begin{array}{c}\text { Control } \\
(\mathbf{n = 5})\end{array}$ \\
\hline $\mathrm{CL}_{\text {oral }}(\mathrm{mL} / \mathrm{min})$ & $115 \pm 12$ & $107 \pm 5$ & $184 \pm 6.2^{*}$ & $114 \pm 40$ \\
\hline $\mathrm{MRT}(\mathrm{min})$ & $50 \pm 3$ & $49 \pm 1$ & $52 \pm 1$ & $53 \pm 9$ \\
\hline $\mathrm{Vd} / \mathrm{F}(\mathrm{L} / \mathrm{kg})$ & $5.7 \pm 0.3$ & $5.3 \pm 0.2$ & $9.6 \pm 0.2$ & $6.2 \pm 3.0$ \\
\hline
\end{tabular}

All of data were shown as mean \pm S.D.

$\mathrm{CL}_{\text {al }}$ : oral clearance rate; MRT: mean residence time; Vd: volume of distribution;

F: bioavailability; SJW: St John's wort

*Statistically significant difference from control (Welch's t-test, $\mathrm{P}<0.05$ )

Table 1: Pharmacokinetic parameters of midazolam.

control group at 7 days; conversely, there was no significant difference between the raspberry ketone-treated and control groups. The MRT was essentially the same in all groups.

\section{Discussion}

Drug-drug and food-drug interactions are two of the most important causes of inter-individual differences in drug efficacy. Tobacco, alcohol, coffee, and other supplements sometimes alter the efficacy of drug therapy. Recently, serious interactions between SJW and clinically important drugs drew our attention to the potential drug interactions of food supplements and herbal medicines. The effects of various herbal medicines on drug-metabolizing enzymes and drug transporters have been reported and are under investigation $[1,5,6]$.

In the present study, the effects of raspberry ketone on the pharmacokinetics of midazolam, a substrate of CYP3A, were investigated. Because raspberry ketone is considered to suppress the accumulation of body fat, it is mainly taken by young healthy women for weight loss. Considering this population, information about the interaction of raspberry ketone with oral contraceptives, which are substrates of CYP3A, is of clinical importance. In the present study, we could not detect any effects of raspberry ketone treatment on the pharmacokinetics of midazolam, even with an extremely high dose (50-fold larger than the usual human dose) for 7 days. Therefore, raspberry ketone seems to have a minimal effect on CYP3A activity, unlike SJW. There have been reported cases of unwanted pregnancies during the concomitant use of SJW and oral contraceptives [14,15]; however, raspberry ketone does not seem to reduce the efficacy of oral contraceptives. Capsaicin, which has a partially similar structural formula to raspberry ketone, reportedly has an inhibitory effect on CYP3A in vitro [16,17]. In a recent study, Zhai et al. [18] reported that the blood concentration of cyclosporine A was significantly increased by capsaicin treatment and, conversely, the mRNA and protein levels of CYP3A and p-glycoprotein (p-gp) in the liver and intestine were decreased by capsaicin treatment [18]. In our study, although we did not evaluate the expression of CYP3A or p-gp, raspberry ketone did not affect the blood concentration of midazolam. This result indicates that raspberry ketone is expected to have no effect on the expression levels or activities of proteins affecting the pharmacokinetics of midazolam. Conversely, because the effect of raspberry ketone on the activities of many CYPs other than CYP3A was not evaluated in this study, we should clarify its impact on those enzymes to characterize further the interaction of raspberry ketone with other drugs. When a drug is administered orally, we must also consider first-pass metabolism. The intestinal and/or hepatic elimination of midazolam may be induced by SJW; however, we could not separate these effects in the present study.

Despite the limitations described above and the small sample size used in the present study, which is considered to lead to a large coefficient of variation for the $\mathrm{CL}_{\text {oral }}$ of midazolam in the SJW control group, we showed that raspberry ketone has little effect on CYP3A activity. We believe that our data provide useful and important information for physicians when prescribing drugs for patients using raspberry ketone.

\section{References}

1. Jiang X, Williams KM, Liauw WS, Ammit AJ, Roufogalis BD, et al. (2004) Effect of St John's wort and ginseng on the pharmacokinetics and pharmacodynamics of warfarin in healthy subjects. Br J Clin Pharmacol 57: 592-599.

2. Wang LS, Zhou G, Zhu B, Wu J, Wang JG, et al. (2004) St John's wort induces both cytochrome P450 3A4-catalyzed sulfoxidation and 2C19-dependent hydroxylation of omeprazole. Clin Pharmacol Ther 75: 191-197.

3. Sugimoto K, Ohmori M, Tsuruoka S, Nishiki K, Kawaguchi A, et al. (2001) Different effects of St John's wort on the pharmacokinetics of simvastatin and pravastatin. Clin Pharmacol Ther 70: 518-524

4. Yue QY, Bergquist C, Gerdén B (2000) Safety of St John's wort (Hypericum perforatum) Lancet 355: 576-577.

5. Dresser GK, Schwarz UI, Wilkinson GR, Kim RB (2003) Coordinate induction of both cytochrome P4503A and MDR1 by St John's wort in healthy subjects. Clin Pharmacol Ther 73: 41-50.

6. Hall SD, Wang Z, Huang SM, Hamman MA, Vasavada N, et al. (2003) The interaction between St John's wort and an oral contraceptive. Clin Pharmacol Ther 74: 525-535.

7. Watanabe T, Kawada T, Kato T, Harada T, Iwai K (1994) Effects of capsaicin analogs on adrenal catecholamine secretion in rats. Life Sci 54: 369-374.

8. Kobayashi A, Osaka T, Namba Y, Inoue S, Lee TH, et al. (1998) Capsaicin activates heat loss and heat production simultaneously and independently in rats. Am J Physiol 275: R92-98.

9. Kawada T, Hagihara K, Iwai K (1986) Effects of capsaicin on lipid metabolism in rats fed a high fat diet. J Nutr 116: 1272-1278.

10. Zhang Z, Hamilton SM, Stewart C, Strother A, Teel RW (1993) Inhibition of liver microsomal cytochrome P450 activity and metabolism of the tobacco-specific nitrosamine NNK by capsaicin and ellagic acid. Anticancer Res 13: 2341-2346.

11. Morimoto C, Satoh Y, Hara M, Inoue S, Tsujita T, et al. (2005) Anti-obese action of raspberry ketone. Life Sci 77: 194-204.

12. SporstøI S, Scheline RR (1982) The metabolism of 4-(4-hydroxyphenyl)butan2-one (raspberry ketone) in rats, guinea-pigs and rabbits. Xenobiotica 12: 249257.

13. Qi JW, Nakamura K, Hosokawa S, Okada Y, Horiuchi R, et al (2005) Timedependent induction of midazolam-1-hydroxylation enzymes in rats treated with St. John's wort. Biol Pharm Bull 28: 1467-1471.

14. Sarino LV, Dang KH, Dianat N, Djihanian H, Natanian N, et al. (2007) Drug interaction between oral contraceptives and St. John's Wort: appropriateness of advice received from community pharmacists and health food store clerks. $J$ Am Pharm Assoc (2003) 47: 42-47.

15. Schwarz UI, Büschel B, Kirch W (2003) Unwanted pregnancy on self-medication with St John's wort despite hormonal contraception. Br J Clin Pharmacol 55: 112-113.

16. Takanohashi T, Isaka M, Ubukata K, Mihara R, Bernard BK (2010) Studies of the toxicological potential of capsinoids, XIII: inhibitory effects of capsaicin and capsinoids on cytochrome P450 3A4 in human liver microsomes. Int J Toxicol 29: $22 \mathrm{~S}-6 \mathrm{~S}$.

17. Babbar S, Chanda S, Bley K (2010) Inhibition and induction of human cytochrome P450 enzymes in vitro by capsaicin. Xenobiotica 40: 807-816.

18. Zhai XJ, Shi F, Chen F, Lu YN (2013) Capsaicin pretreatment increased the bioavailability of cyclosporin in rats: involvement of P-glycoprotein and CYP $3 \mathrm{~A}$ inhibition. Food Chem Toxicol 62: 323-328. 